\title{
Prevention of Hepatic Tumor Metastases in Rats with Herpes Viral Vaccines and $\gamma$-Interferon
}

\author{
Howard M. Karpoff, ${ }^{\star}$ Michael D’Angelica, ${ }^{\star}$ Sarah Blair, ${ }^{\star}$ Michael D. Brownlee, ${ }^{\S}$ Howard Federoff, ${ }^{\ddagger}$ and Yuman Fong ${ }^{\star}$ \\ *Department of Surgery, Memorial Sloan-Kettering Cancer Center, New York 10021; ${ }^{\ddagger}$ Department of Neurology, Medicine, \\ Microbiology, and Immunology, University of Rochester, Rochester, New York 14627; ${ }^{\S}$ Department of Medicine, Albert Einstein College \\ of Medicine, Bronx, New York 10461
}

\begin{abstract}
Previous studies showed that $\gamma$ IFN decreases metastatic hepatic tumor growth by stimulating Kupffer cells (KC). The present studies examine whether lymphocyte stimulation via cells engineered to secrete GM-CSF or IL-2 decreases hepatic tumor growth, and whether stimulation of both macrophages and lymphocytes is more effective than either individually. Rats were immunized with irradiated hepatoma cells transduced by herpes viral amplicon vectors containing the genes for GM-CSF, IL-2 or LacZ. On day 18, half of each group was treated with $5 \times 10^{4} \mathrm{U} \gamma \mathrm{IFN}$, or saline intraperitoneally for $3 \mathrm{~d}$. On day 21 , all rats received $5 \times 10^{5}$ hepatoma cells intrasplenically. On day 41, rats were killed and tumor nodules were counted. Separate rats underwent splenocyte and $\mathrm{KC}$ harvest for assessment of lymphocyte- and macrophage-mediated tumor cell kill in vitro. GM-CSF or IL-2 vaccines or $\gamma$ IFN decreased tumor nodules significantly (GM-CSF $13 \pm 4$, IL-2 $14 \pm 6$ vs. control $75 \pm 24, P<0.001)$. Combination therapy was more effective, and completely eliminated tumor in 4 of 12 IFN-GM-CSF and 8 of 11 IFN-IL-2 animals. Additional rats underwent partial hepatectomy, an immunosuppressive procedure known to accelerate the growth of hepatic tumor, following tumor challenge. Therapy was equally effective in this immunosuppressive setting. Vaccination is associated with enhancement of splenocyte-mediated tumoricidal activity, whereas the effect of $\gamma$ IFN is mediated by KC. GM-CSF and IL-2 vaccine therapy and pretreatment with $\gamma$ IFN represent effective strategies in reducing hepatic tumor. Combination therapy targets both lymphocytes and macrophages, and is more effective in reducing tumor than either therapy alone. (J. Clin. Invest. 1997. 99:799-804.) Key words: hepatectomy • IL-2 • GM-CSF • liver • HSV
\end{abstract}

\section{Introduction}

Hepatic tumors are the most common gastrointestinal tract malignancy worldwide (1). Surgical resection is the most effec-

\footnotetext{
Presented at the 87th annual meeting of the American Association for Cancer Research, 20-24 April 1996, Washington, DC.

Address correspondence to Yuman Fong, M.D., 1275 York Ave., New York, NY 10021. Phone: (212) 639-2016; FAX: (212) 794-5852; E-mail: FongY@MSKCC.org

Received for publication 6 August 1996 and accepted in revised form 9 December 1996.
}

J. Clin. Invest.

(C) The American Society for Clinical Investigation, Inc. 0021-9738/97/02/0799/06 \$2.00

Volume 99, Number 4, February 1997, 799-804 tive treatment for hepatic tumors; however, recurrence is frequent and usually occurs in the liver (2). In addition, resection, a procedure commonly used as therapy for liver cancer, may accelerate the growth of local residual cancer $(3,4)$. Previous studies in our laboratory demonstrated that enhancement of Kupffer cell $(\mathrm{KC})^{1}$ tumoricidal activity by systemic administration of the immunomodulator $\gamma$ IFN significantly reduces the uptake and growth of hepatic tumor found in a metastatic model (4). The current study attempts to determine if stimulation of the lymphocyte antitumor mechanisms is complementary to the macrophage tumoricidal mechanisms.

One of the most successful strategies directed at stimulating lymphocyte antitumor immunity is the use of cytokines, such as IL-2 and GM-CSF. IL-2 is a protein (synthesized and secreted primarily by $\mathrm{T}$ helper cells) which activates lymphocytes (5); GM-CSF is produced by a wide range of cell types including B and T cells, macrophages, and endothelial cells, and it functions to stimulate proliferation, maturation, and function of hematopoietic cells (6). The high systemic levels of cytokines required to produce an antitumor response in humans have led researchers to examine whether local cytokine production in the presence of tumor antigens could be effective without the toxicity associated with high systemic levels (7). Several gene therapy models utilizing IL-2- and GM-CSFsecreting tumor vaccines have demonstrated these cytokines' ability to stimulate the immune system, and to produce protective immunity in both rat and murine systems (8-12).

Herpes Simplex virus amplicon (HSV) vectors are efficient vehicles for introducing foreign genes into cells. HSV vectors rapidly infect cells, transducing them in a matter of minutes with high local expression of the foreign gene for a limited duration (13-15). In the current experiments, this transient expression allows us to distinguish immunologic responses from effects due to ongoing cytokine production. We constructed replication-defective HSV amplicon vectors containing the genes for IL-2, GM-CSF, or LacZ in order to examine whether gene799 therapy with tumor cells tailored by HSV vectors to produce cytokines could induce immunity and decrease metastatic tumor uptake and growth. We sought to determine if targeting both lymphocyte function and macrophage function is more effective than either alone, and to examine the relative roles of each in decreasing tumor growth. Furthermore, since partial hepatectomy $(\mathrm{PH})$ has been shown to be immunosuppressive and to accelerate the growth of hepatic tumor, we examined the effectiveness of these treatment strategies in the clinically relevant model of hepatic resection in the face of microscopic residual disease.

1. Abbreviations used in this paper: HSV, Herpes Simplex virus; KC, Kupffer cells; PH, partial hepatectomy. 


\section{Materials and Methods}

Animals. Male Buffalo rats (National Cancer Institute, Bethesda, $\mathrm{MD})$ were housed in individual cages in a temperature- $\left(22^{\circ} \mathrm{C}\right)$ and humidity-controlled room with a 12 -h day/night cycle. Animals were provided food (PMI Mills, St. Louis, MO) and water ad libitum. Food consumption and body weight were measured daily. All animals received care under approved protocols in compliance with Memorial Sloan-Kettering Cancer Center's Institutional Animal Care and Use Committee guidelines.

Tumors. A syngeneic tumor, Morris Hepatoma McA-RH7777 (ATCC No. CRL 1601; Rockville, MD), was maintained in culture and periodically implanted in flanks to ensure tumorigenicity.

Recombinant murine $\gamma I F N$. Recombinant murine $\gamma$ IFN supplied by Genentech Inc. (South San Francisco, CA) was diluted with sterile water to $5 \times 10^{4} \mathrm{U} / 100 \mathrm{ml}$ before injection. This dosage has previously been shown to produce significant biological responses including enhanced expression of TNF $\alpha$ receptors $(16,17)$.

Operative procedures. All operative procedures were performed under pentobarbital anesthesia ( $25 \mathrm{mg} / \mathrm{kg}$ of body weight i.p.) via midline abdominal incision. $70 \% \mathrm{PH}$ was performed according to the methods of Higgins and Anderson and include resection of the left and median lobes (2). Animals received $3 \mathrm{ml}$ i.p. of normal saline prior to skin closure.

Splenocyte isolation. Animals underwent splenectomy under sterile conditions. Each spleen was placed in a petri dish with $10 \mathrm{ml}$ of media (RPMI $+10 \%$ FCS $+50 \mu \mathrm{g} / \mathrm{ml}$ gentamicin). Splenocytes were washed from the spleen by repeated resuspension with media, spun (1,500 rpm, $5 \mathrm{~min}$ ) and subsequently resuspended in $5 \mathrm{ml}$ of red cell lysis solution ( $8.8 \mathrm{~g} \mathrm{NaCl}, 50 \mathrm{mM}$ Tris, $10 \mathrm{ml} \mathrm{NP}-40,1.68 \mathrm{~g} \mathrm{NaF}$ per liter). After $1 \mathrm{~min}$, the solution was neutralized by the addition of $5 \mathrm{ml}$ of media. Cells were spun $(1,500 \mathrm{rpm}, 10 \mathrm{~min})$, washed $2 \times$ with media, and kept in culture in media supplemented with $30 \mathrm{U} / \mathrm{ml} \mathrm{IL-2}$ (Chiron Corp., Emeryville, CA) for $2 \mathrm{~d}$ prior to use.

Kupffer cell isolation. KC were obtained with standard collagenase perfusion and differential ultracentrifugation $(18,19)$. Briefly, the portal vein was cannulated and the liver perfused in vivo with three different solutions: Leffert's solution with $0.5 \mathrm{mM} /$ liter EGTA $\left(38^{\circ} \mathrm{C}, 10 \mathrm{~min}\right)$, Leffert's solution without EGTA $\left(38^{\circ} \mathrm{C}, 5 \mathrm{~min}\right)$, and Leffert's solution with $5 \mathrm{mM} /$ liter $\mathrm{CaCl}_{2}, 7 \mathrm{mg} / \mathrm{ml}$ bovine serum albumin and $0.2 \mathrm{mg} / \mathrm{ml}$ collagenase D (Boehringer Mannheim Co., Indianapolis, IN) $\left(38^{\circ} \mathrm{C}, 15 \mathrm{~min}\right)$. The liver was then removed, minced, passed through a 50- $\mu$ m nylon mesh into RPMI and centrifuged $(50 \mathrm{~g}$, $2 \mathrm{~min}$ ). The supernatant was centrifuged $(300 \mathrm{~g}, 10 \mathrm{~min})$, and the pellet containing $\mathrm{KC}$ was resuspended in $20 \mathrm{ml}$ of Media, layered onto an isoosmotic Percoll (Pharmacia Biotech Inc., Piscataway, NJ) gradient, and spun ( $800 \mathrm{~g}, 15 \mathrm{~min})$. The band containing $\mathrm{KC}$ was harvested, diluted with equal volume PBS, and spun $(800 \mathrm{~g}, 10 \mathrm{~min})$. The pellet was resuspended in media $+1 \%$ penicillin/streptomycin. Cells were counted, plated in 96-well plates (Costar Corp., Cambridge, MA), and incubated for $4 \mathrm{~h}$. Non-adherent cells were washed off with media. This procedure yields cells which adhere, take up India ink uniformly, and stain positive with Wright-Giemsa stain (Baxter, McGaw Park, IL), confirming this procedure produced $\mathrm{KC}$.

$H S V$ vectors. The murine GM-CSF, human IL-2 and $L a c Z$ genes were cloned directionally into HSVprPUC which contains the HSV immediate early $4 / 5$ promoter, a multiple cloning site, and an SV40 A sequence, and packaged as previously described (13). RR1 cells (BHK cells stably transfected with the HSV IE3 gene) (20), along with D30 EBA helper virus (21) (a strain 17-derived IE3 mutant deleted from codons 83 to 1236 and maintained in Dulbecco's modified Eagle medium (DME) containing high glucose [HG, $4.5 \mathrm{~g} / \mathrm{liter}$ ], 10\% FCS, $1 \%$ penicillin/streptomycin, and $400 \mu \mathrm{g} / \mathrm{ml}$ of bioactive geneticin [G418; Gibco BRL, Gaithersburg, $\mathrm{MD}$ ] at $37^{\circ} \mathrm{C}$ and $5 \% \mathrm{CO}_{2}$ ) were used for packaging HSV amplicons. To package amplicon vectors, $3 \times 10^{6} \mathrm{RR} 1$ cells were plated in media containing $10 \% \mathrm{FCS}$ and transfected $4 \mathrm{~h}$ later by adding $40 \mu \mathrm{l}$ of Lipofectin (Gibco), waiting 5 min, and adding amplicon DNA solution dropwise $(30 \mu \mathrm{g}$ at $1 \mu \mathrm{g} / \mu \mathrm{l}$ in DME). $6 \mathrm{~h}$ later, plates were fed with media containing 5\% FCS. $20 \mathrm{~h}$ after transfection, D30 EBA virus in 50-100 $\mu \mathrm{l}$ was added to achieve an moi of $0.2 .5 \mathrm{ml}$ of complete media with 5\% FCS were added to each plate after $1 \mathrm{~h}$, and amplicon virus stocks were harvested $2 \mathrm{~d}$ later. After overnight storage at $70^{\circ} \mathrm{C}$, fresh RR1 cells $(4 \times$ $10^{6}$ cells $/ 60 \mathrm{~mm}$ plate) were infected with warmed $\left(34^{\circ} \mathrm{C}\right)$, sonicated virus stock. $2 \mathrm{~d}$ later, stocks were harvested and stored for subsequent use. HSVlac stocks were titered by an expression assay using NIH$3 T 3$ cells plated $\left(2 \times 10^{5}\right.$ cells/well of a 24 -well plate $)$ and infected with increasing volumes of virus stock in duplicate. $24 \mathrm{~h}$ after infection, cells were fixed and stained with 5-bromo-4-chloro-3-indolyl $\beta$-D-galactoside (X-gal) using standard methods. The number of $\mathrm{X}$-gal+ (blue) cells were counted, and titers were expressed as the number of blue forming units/ml. The D30 EBA helper virus in each stock was titered by plaque assay on RR1 cells, and the cytokine-containing vectors were titered by slot blot analysis (22). For slot blot analysis, viral DNA was extracted twice from packaged virus by phenol/chloroform, ethanol-precipitated with single-strand calf thymus DNA as carrier, denatured at room temperature with $0.2 \mathrm{~N} \mathrm{NaOH}$, $0.5 \mathrm{M} \mathrm{NaCl}$ for $10 \mathrm{~min}$, and loaded on a nylon membrane with a slot blot apparatus. The membrane was backed for $2 \mathrm{~h}$ at $65^{\circ} \mathrm{C}$ and probed with a [ $\left.{ }^{32} \mathrm{P}\right]$-labeled $435 \mathrm{bp} \mathrm{SspI}$ and PvuI fragment containing part of the $\beta$-lactamase gene from pBR322 (nucleotides 3733-4168). After stringent washing $(0.1 \times$ SSC $2 \times$ for $15 \mathrm{~min})$, blots were exposed to $\mathrm{x}$-ray film, and various timed exposures taken and densitometrically scanned (LKB Ultroscan; Pharmacia LKB Biotechnology Inc., Piscataway, NJ). Band densities and the titers of HSVil2 and HSV GM-CSF (expressed as particles/ml) calculated from the density relative to HSVlac given that this latter amplicon was titered by an expression assay, were compared. HSVlac titers were between $1-2 \times$ $10^{6}$ blue forming units $/ \mathrm{ml}$ as titered by expression and X-gal biochemistry on NIH 3 T3 cells. The HSVil2 and HSVGM-CSF titers were between $1-2 \times 10^{6}$ particles $/ \mathrm{ml}$. The ratio of D30 EBA helper virus to amplicon varied from 2:1 to 5:1. moi refers to the amplicon. Recombination for wild-type revertants was monitored by plaque assay on Vero cells and occurred at a frequency of $1 \times 10^{-6}$.

In vitro production of cytokines. To assess in vitro production of cytokines, $10^{6}$ hepatoma cells per $2 \mathrm{ml}$ were plated in six-well plates (Costar), irradiated with 10,000 rad, and rested for $1 \mathrm{~h}$. Cells were then exposed to HSVil2, HSVGM-CSF, HSVlac, or Media for $20 \mathrm{~min}$ at moi's of one and two and washed $2 \times$ with media. Cell culture supernatants were harvested on days 1,2, 4, and 7 post-exposure, and cytokine levels were measured by ELISA (IL-2, R \& D Systems, Minneapolis, MN; GM-CSF, Genzyme Corp., Cambridge, MA).

Effect of vaccination and $\gamma I F N$ on hepatic tumor. Hepatoma cells in culture were irradiated with 10,000 rad, allowed to rest for $1 \mathrm{~h}$, then exposed to HSVil2, HSVGM-CSF, HSVlac or media for $20 \mathrm{~min}$ at an moi of one. Cells were then washed $2 \times$ with media, and $10^{6}$ cells/ $200 \mu \mathrm{l}$ were injected intrasplenically. Preliminary experiments in our laboratory have demonstrated intrasplenic vaccination to be more effective than either intraperitoneal or subcutaneous vaccination. An additional control group underwent injection of media alone. On day 18 , half the animals in each group received either $5 \times 10^{4} \mathrm{U}$ of $\gamma \mathrm{IFN}$ i.p. or normal saline for $3 \mathrm{~d}$. On day 21 , all animals received a challenge of $5 \times 10^{5}$ hepatoma cells/200 $\mu \mathrm{l}$ intrasplenically followed by splenectomy $10 \mathrm{~min}$ later, allowing sufficient time for the hepatoma cells to migrate to the liver (23). Animals were killed $20 \mathrm{~d}$ later, and tumor nodules were counted. Additional animals were vaccinated, killed on $\mathrm{d} 2$ and 18 post-vaccination, and heart, lung, liver, kidney and serum harvested for assessment of in vivo production of cytokines by ELISA.

Effect of immunization and $\gamma I F N$ on hepatectomy-enhanced tumor growth. To assess the effects of vaccination on tumor growth in the setting of $\mathrm{PH}$, animals were immunized intrasplenically with hepatoma vaccines (HSVil2, HSVGM-CSF, HSVlac) produced as above. On day 18 , half the animals in each group received either $5 \times$ $10^{4} \mathrm{U}$ of $\gamma \mathrm{IFN}$ intraperitoneally, or normal saline for $3 \mathrm{~d}$. On day 21, all animals received a challenge of $5 \times 10^{5}$ hepatoma cells/200 $\mu \mathrm{l}$ in- 
trasplenically followed by splenectomy $10 \mathrm{~min}$ later. Half the animals in each group underwent $70 \% \mathrm{PH} 1 \mathrm{~h}$ after tumor injection. One control group did not undergo vaccination or PH. Animals were killed $18 \mathrm{~d}$ after tumor challenge, and nodules were counted. In previous experiments (unpublished data), the number of surface nodules was shown to correlate directly with tumor volume as measured by water displacement.

Effect of vaccination and $\gamma I F N$ on splenocyte and KC function. Animals in each treatment group underwent vaccination and $\gamma$ IFN treatment as above, and splenocytes and $\mathrm{KC}$ were harvested on day 21 post-vaccination. Tumoricidal activity was assessed by mixing effectors with Europium-labeled tumor cells in an in vitro assay. Labeled cells were plated at a concentration of $5 \times 10^{4}$ cells $/ 100 \mu l$ per well in a 96-well U-Bottom plate (Costar) containing effector cells in wells at varying effector to target ratios. The plate was spun $(200 \mathrm{rpm}$, $5 \mathrm{~min}$ ), incubated $\left(4 \mathrm{~h}, 37^{\circ} \mathrm{C}\right)$, and respun (500 rpm, $\left.5 \mathrm{~min}\right) .20 \mu \mathrm{l}$ of supernatant were transferred to a 96-well Flat Bottom plate (Costar) already containing $180 \mu \mathrm{l} /$ well of Delfia Enhancement Solution (Wallac Oy, Turku, Finland). The plate was read in a 1232 Delfia Fluorometer (Wallac Oy). Maximum lysis was measured by lysing cells with $1 \%$ Triton $\mathrm{X}$. Percent specific lysis is equal to experimental spontaneous release/max. release - spontaneous release $\times 100$. Spontaneous release varied between 5 and $15 \%$ of max. Assays were performed in triplicate.

Statistical analysis. Statistical significance of differences in the number of liver nodules and percent specific lysis, expressed as mean \pm SEM, were analyzed using ANOVA or Student's $t$-test (SPSS Inc., Chicago, IL) as appropriate.

\section{Results}

In vitro and in vivo production of cytokines. Control cells not exposed to cytokine gene-containing vectors do not produce cytokines including IL-2, GM-CSF, $\gamma$ IFN, IL-12, or TNF $\alpha$. No cytokines are seen immediately after transduction with HSVil2 and HSVGM-CSF and washing, indicating that proteins were not injected along with tumor cells. Cells exposed to HSVil2 or HSVGM-CSF produce nanogram quantities of these cytokines per $10^{6}$ cells after vaccination (Figs. $1, A$ and $B$ ), peaking on day 1 and decreasing thereafter. The in vitro data correlate with the in vivo data: cytokines levels are seen only in the liver (IL-2, $461 \mathrm{pg} /$ organ) and spleen (IL-2, $12 \mathrm{pg} /$ organ) on day 2, but levels are below detectability on day 18. Cytokine levels were undetectable in heart, lung, serum, and kidney.

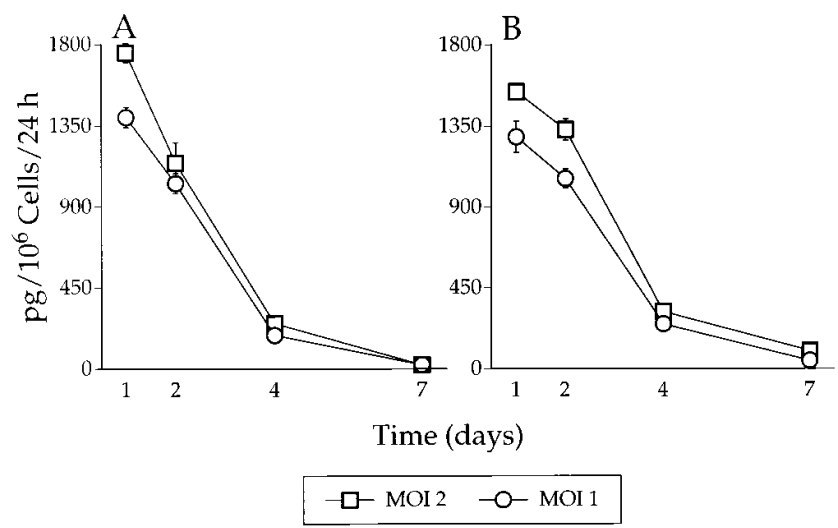

Figure 1. In vitro production of GM-CSF and IL-2. $10^{6}$ irradiated Morris hepatoma cells were exposed to HSVGM-CSF $(A)$ or HSVil2 $(B)$ for $20 \mathrm{~min}$ at multiplicities of infection of two $(\square)$ and one $(\bigcirc)$. Supernatants were evaluated for cytokine production by ELISA.

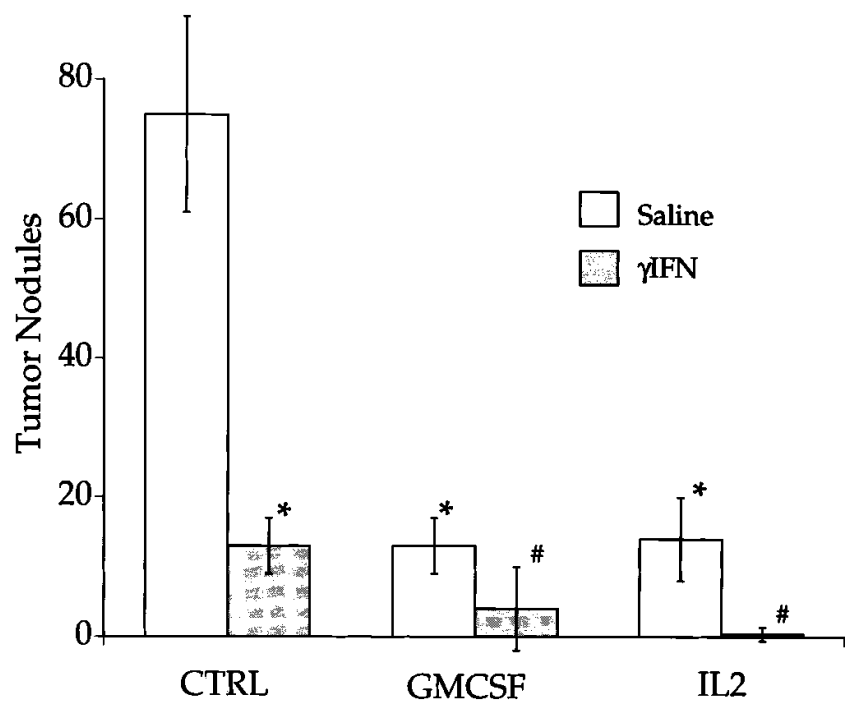

Figure 2. HSV tumor vaccines and $\gamma$ IFN reduce tumor burden. Animals underwent vaccination with irradiated cells transduced by either HSVGM-CSF (GM-CSF) or HSVil2 (IL-2). Controls (CTRL) consisted of vaccination with cells transduced by HSVlac, non-transduced cells, or media. On day 18 after vaccination, half of each group was treated preoperatively with either $50,000 \mathrm{U} \gamma \mathrm{IFN}$ or saline for 3 d. On day 21, all animals were challenged intrasplenically. Animals were killed $21 \mathrm{~d}$ after challenge, and tumor nodules were counted. There were no significant differences among any of the three control groups; to simplify the illustration, the three control groups have been pooled. ${ }^{*} P<0.01$ vs. CTRL/IFN; ${ }^{*} P<0.01$ vs. CTRL/Sal; $n=11$ to 13 per group. GM-CSF/IFN, 4/12 without tumor; IL-2/IFN, $8 / 11$ without tumor.

Effect of vaccination and $\gamma I F N$ on hepatic tumor. There was no significant effect of vaccination with irradiated cells or vaccination with irradiated cells transduced by HSVlac compared to injection of media alone. Animals immunized with IL-2- or GM-CSF-secreting cells or pretreated with $\gamma$ IFN had significantly fewer tumor nodules than all three control groups (Fig. $2, P<0.001)$. Combination treatment with IL-2- or GM-CSFsecreting tumor cell vaccines and pretreatment with $\gamma$ IFN was more effective than any single treatment; complete responses were seen in 8 of 11 IL- 2 animals and 4 of 12 GM-CSF animals (Fig. 2). No animal treated with $\gamma$ IFN alone was without tumor.

Effect of immunization and $\gamma I F N$ on hepatectomy-enhanced tumor growth. Hepatectomy significantly increased the number of tumor nodules compared to controls (Fig. 3, NoHep vs. CTRL/Sal, $P<0.001$ ). Animals immunized with IL-2- or GMCSF-secreting cells or pretreated with $\gamma$ IFN had significantly fewer tumor nodules than control (Fig. 3, CTRL/Sal vs. all others $P<0.001)$. Combination treatment with cytokine-secreting vaccines and pretreatment with $\gamma$ IFN was more effective than any single treatment. (Fig. $3, P<0.01$ ). Thus, combination therapy of cytokine vaccines and $\gamma$ IFN is effective in decreasing tumor growth in the setting of hepatectomy.

Effect of vaccination and $\gamma I F N$ on splenocyte and $K C$ function. Vaccination with HSVlac or irradiated cells had no significant effect on either KC or splenocyte activity. Splenocytes from animals vaccinated by either HSVil2 or HSVGM-CSF had significantly greater killing of targets than splenocytes from control or $\gamma$ IFN-treated animals (Figs. $4, A$ and $B$ ). $\gamma$ IFN did not appear to affect splenocyte lytic activity. 


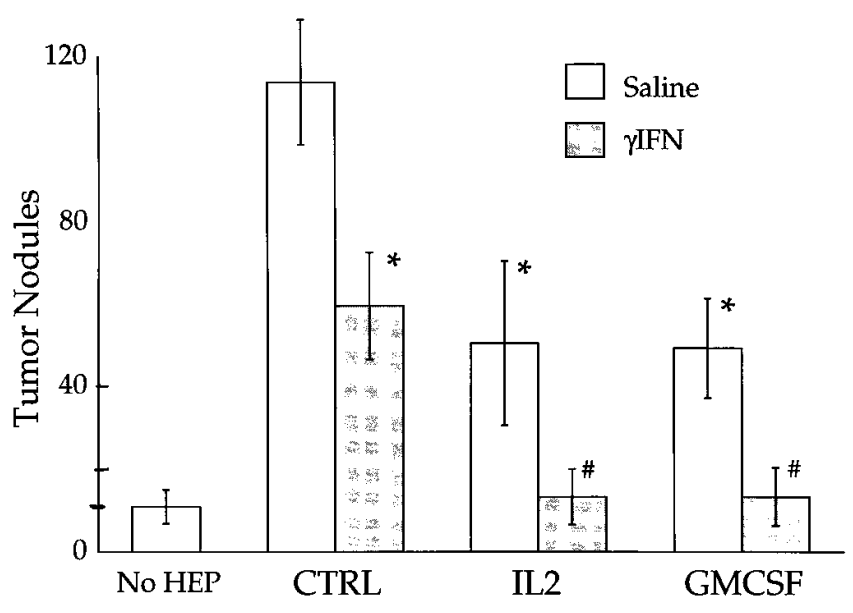

Figure 3. HSV vaccines and $\gamma \mathrm{IFN}$ reduce the effect of hepatectomy on tumor growth. Animals underwent vaccination with irradiated cells transduced by either HSVGM-CSF (GM-CSF) or HSVil2 $(I L-2)$. Controls $(C T R L)$ consisted of vaccination with cells transduced by HSVlac. On day 18 after vaccination, half of each group was treated preoperatively with either 50,000 U $\gamma$ IFN or saline. On day 21 all animals underwent tumor challenge intrasplenically, followed $1 \mathrm{~h}$ later by $70 \%$ partial hepatectomy. One control group did not undergo hepatectomy (No Hep). Animals were killed $19 \mathrm{~d}$ after challenge, and tumor nodules were counted. ${ }^{*} P<0.01$ vs. CTRL/IFN; $* P<0.01$ vs. $\mathrm{CTRL} / \mathrm{Sal} ; n=$ five per group.

$\mathrm{KC}$ from rats pretreated with $\gamma \mathrm{IFN}$ had significantly greater killing of targets than $\mathrm{KC}$ from controls (Figs. 5, $A$ and $B)$. KC from rats vaccinated with $\mathrm{HSVil2}$ also had significantly greater killing of targets than $\mathrm{KC}$ from controls $(P<0.05)$, but not as great as $\gamma$ IFN. Vaccines secreting GM-CSF did not seem to affect $\mathrm{KC}$ activity.

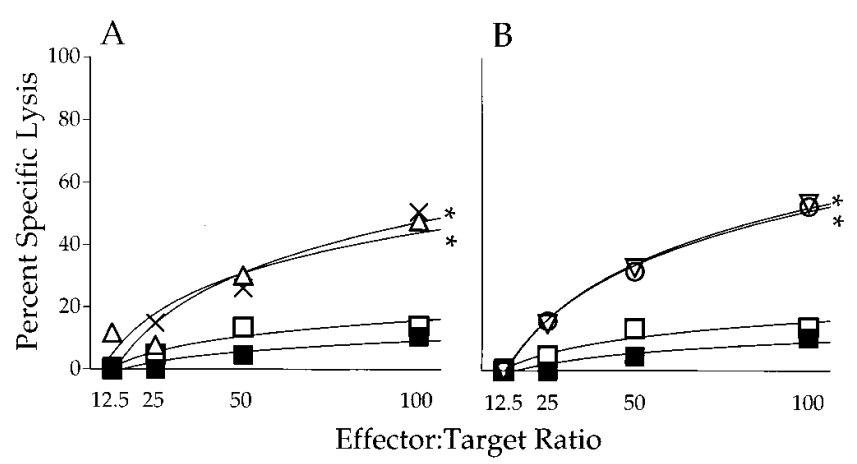

$$
\begin{aligned}
& -\square \text { CTRL } \triangle \text { IL2 } \rightarrow \text { IFN/IL2 } \\
& \square \text { IFN } \rightarrow-\text { GMCSF }-\mathrm{O}-\text { IFN/GMCSF }
\end{aligned}
$$

Figure 4. HSV tumor vaccines stimulate splenocyte antitumor activity. (A) Splenocytes harvested from animals vaccinated with irradiated cells transduced by HSVil2, from animals vaccinated and treated with $\gamma$ IFN, from animals treated with $\gamma$ IFN alone, or from salinetreated controls. $(B)$ Splenocytes harvested from animals vaccinated with irradiated cells transduced by HSVGM-CSF, from animals vaccinated and treated with $\gamma$ IFN, from animals treated with $\gamma$ IFN alone, or from saline-treated controls. Animals vaccinated with irradiated cells transduced by either HSVil2 $(A)$ or HSVGM-CSF $(B)$ had significantly-increased splenocyte cytolytic activity $\left({ }^{*} P<0.05\right)$. $\gamma$ Interferon did not alter splenocyte activity.

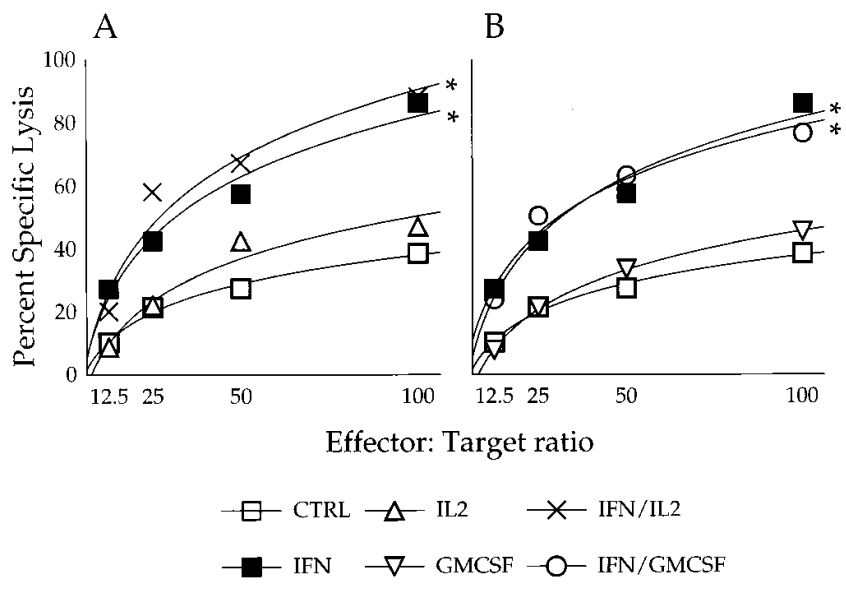

Figure 5. Lysis of Morris hepatoma cells by Kupffer Cells $(K C)$. $(A)$ $\mathrm{KC}$ harvested from animals vaccinated with irradiated cells transduced by HSVil2, from animals vaccinated and treated with $\gamma$ IFN, from animals treated with $\gamma$ IFN alone, or from saline-treated controls. $(B) \mathrm{KC}$ harvested from animals vaccinated with irradiated cells transduced by HSVGM-CSF, from animals vaccinated and treated with $\gamma$ IFN, from animals treated with $\gamma$ IFN alone, or from salinetreated controls. KC harvested from animals treated with $\gamma$ IFN had significantly-increased $\mathrm{KC}$ cytolytic activity $(* P<0.05)$. Vaccination with irradiated cells transduced by either HSVil2 $(A)$ or HSVGMCSF $(B)$ had no effect on KC activity.

\section{Discussion}

Recent studies have focused on the use of cytokines to enhance the immune system in an attempt to decrease tumor growth $(8,9,24)$. Systemic administration of cytokines is accompanied by unwanted serious side effects $(5,7)$. Transfer of cytokine genes into tumor cells gives the advantage of being able to produce high concentrations of cytokines of interest in the area of putative tumor antigens. Also, as identification of specific cytokine genes increases, we are able to transfer specific isolated genes to determine their role in immunomodulation.

The fundamental principles of immunotherapy for solid tumors are the suppositions that tumor antigens can be recognized, and that animals can elicit a tumor-specific immune response $(5,25)$. In this experiment, we vaccinated animals with irradiated tumor cells that had been infected by HSV vectors, and were producing IL-2 or GM-CSF (cytokines which have been shown previously to stimulate antitumor immune responses) (8-11, 26).

HSV vectors are efficient and effective in producing high levels of cytokines locally and generating an immune response $(13,14,27)$. In this experiment, cytokine production was seen only in the target organs, the liver and the spleen. Furthermore, production was transient, with levels returning to below detectability prior to the subsequent tumor challenge $3 \mathrm{wk}$ later. Thus, any effects on cellular immunity and tumor growth were not dependent upon ongoing cytokine production during challenge.

Vaccination with HSVil2 or HSVGM-CSF reduced the amount of tumor in the liver after subsequent challenge with highly tumorigenic doses of unmodified tumor cells. The results are not simply due to the prior presence of tumor antigen, since irradiated cells alone did not reduce tumor. Nor was the 
effect of vaccination due to the presence of HSV, since treatment with HSVlac did not cause a decrease in tumor. Even in the setting of $\mathrm{PH}$, which has been shown to be immunosuppressive and to accelerate the growth of hepatic tumor, vaccination was effective. Combination therapy abrogated the effect of $\mathrm{PH}$, for animals so treated had no more tumor than the non-hepatectomized control.

Production of cytokines in the presence of tumor antigens induces a lymphocyte immune response, as evidenced by the increased tumoricidal activity of splenocytes from vaccinated animals. Generating an immune response requires a simple vaccination protocol utilizing fresh tumor cells, a 20-min transduction, and a single injection into the spleen and portal system to result in finite cytokine production. Such a protocol is clinically feasible.

Perioperative immunostimulation has been examined as a means of decreasing tumor $(28,29)$. In the current study, we employed $\gamma$ IFN, a multifunctional protein with a wide range of immunostimulatory effects, for immunoactivation $(26,30)$. In this experiment, pretreatment with $\gamma \mathrm{IFN}$ resulted in decreased hepatic tumor after splenic injection of tumor. This effect is due to stimulation of $\mathrm{KC}$ causing increased tumoricidal activity of these tissue-based macrophages $(4,26)$.

The combination of IL- 2 and $\gamma$ IFN has begun to be examined in clinical trials (31). In the current study, the combination of $\gamma$ IFN and cytokine vaccines was more effective than either method alone, and, in many cases, prevented the establishment and growth of tumor in the liver after subsequent challenge with highly tumorigenic doses of unmodified tumor cells. Whether these effects were synergistic or simply additive is difficult to distinguish. $\gamma \mathrm{IFN}$ did not appear to increase the tumoricidal activity of splenocytes; the cytokine vaccines appeared to have little direct effect on macrophages. However, in addition to augmenting macrophage kill, $\gamma$ IFN may also improve antigen processing, thereby increasing the efficiency of T-cell mediated immunity.

Liver cancer effects over 2 million people worldwide per year. Surgical resection is the most effective treatment, yet the most common site for recurrence after resection is within the liver itself, indicating that microscopic residual disease is left behind after "curative" surgery. Experimental evidence indicates that hepatic resection is immunosuppressive and enhances the growth of residual tumor $(19,32)$. The current experiment confirms that tumor growth in the liver is enhanced by $\mathrm{PH}$. Moreover, the current study demonstrates that even in the immunosuppressive setting of liver resection, macrophage, and lymphocyte anti-tumor function can be restored by $\gamma$ IFN administration and tumor immunization.

Clinical studies have already shown the feasibility of extracting tumor, transducing cells with genes, and returning the transduced cells to the host (33); HSV vectors are potentially useful tools for this clinical application because they can transfect irradiated, non-replicating cells rapidly and efficiently. In experiments using human tumors isolated from patients in the operating room, the entire isolation, transduction with HSV vectors, and irradiation process was uniformly less than 240 min, and was free of the technical problems of primary tissue culture (34). $\gamma$ IFN has been used in clinical trials for several years with varying effectiveness as a therapeutic tool for large tumor burdens. In our clinically relevant model of hepatectomy and local recurrence, these two treatments retarded growth of microscopic residual metastases. These data encour- age future studies of the use of an immunomodulator, such as $\gamma I F N$, coupled with directed vaccine gene therapy in the adjuvant treatment of the large numbers of patients undergoing liver resection for cancers.

\section{References}

1. Lotze, M.T., J.C. Flickinger, and B.I. Car. 1993. Hepatobiliary neoplasms. In Principles of Oncology. V.T. Devita, S. Hellman, and S.A. Rosenberg, editors. J.B. Lippincott Co., Philadelphia. 883-914.

2. Zhou, X.D., Y.Q. Yu, Z.Y. Tang, B.H. Yang, J.Z. Lu, Z.Y. Lin, Z.C. Ma, D.B. Xu, B.H. Zhang, Y.X. Zheng, et al. 1993. Surgical treatment of recurrent hepatocellular carcinoma. Hepato-Gastroenterology. 40:333-336.

3. Loizidou, M.C., R.J. Lawrance, S. Holt, N.J. Carty, A.J. Cooper, P. Alexander, and I. Taylor. 1991. Facilitation by partial hepatectomy of tumor growth within the rat liver following intraportal injection of syngeneic tumor cells. Clin. Exp. Metastasis. 9:335-349.

4. Karpoff, H.M., C. Tung, B. Ng, and Y. Fong. 1996. $\gamma$-Interferon protects against hepatic tumor growth in rats by increasing Kupffer cell tumoricidal activity. Hepatology. 24(2):374-379.

5. Rubin, J.T. 1993. Interleukin-2: Its biology and clinical application in patients with cancer. Cancer Invest. 11:460-472.

6. Jones, T., A. Stern, and R. Lin. 1994. Potential role of granulocyte-macrophage colony-stimulating factor as a vaccine adjuvant. [Review]. Eur. J. Clin. Microbiol. Infect. Dis. 13(2):47S-53S. 7. 39 .

7. Rosenberg, S.A. 1990. Adoptive immunotherapy for cancer. Sci Am. 262:

8. Bubenik, J., N.N. Voitenok, J. Kieler, V.S. Prassolov, P.M. Chumakov, D. Bubenikova, J. Simova, and T. Jandlova. 1988. Local administration of cells containing an inserted IL-2 gene and producing IL-2 inhibits growth of human tumors in nu/nu mice. Immunol. Lett. 19:279-283.

9. Gansbacher, B., L. Zier, B. Daniels, K. Cronin, R. Bannerji, and E. Gilboa. 1990. Interleukin-2 gene transfer into tumor cells abrogrates tumorigenicity and induces protective immunity. J. Exp. Med. 172:1217-1224.

10. Vieweg, J., F.M. Rosenthal, R. Bannerji, W.D.W. Heston, W. Fair, B. Gansbacher, and E. Gilboa. 1994. Immunotherapy of prostate cancer in the Dunning rat model: Use of cytokine gene modified tumor vaccines. Cancer Res. 54:1760-1765.

11. Dranoff, G., E. Jaffee, A. Lazenby, P. Golumbek, H. Levitsky, K. Brose, V. Jackson, H. Hamada, D. Pardoll, and R.C. Mulligan. 1993. Vaccination with irradiated tumor cells engineered to secrete murine granulocyte-macrophage colony-stimulating factor stimulates potent, specific, and long-lasting antitumor immunity. Proc. Nat. Acad. Sci. USA. 90:3539-3543.

12. Abe, J., H. Wakimot, Y. Yoshida, M. Aoyagi, K. Hirakawa, and H. Hamada. 1995. Antitumor effect induced by granulocyte/macrophage-colony-stimulating factor gene-modified tumor vaccination: comparison of adenovirus- and retrovirus-mediated genetic transduction. J. Cancer Res. Clin Oncol. 121:587592.

13. Geller, A.I., K. Keyomarsi, J. Bryan, and A.B. Pardee. 1990. An efficient deletion mutant packaging system for defective herpes simplex virus vectors: Potential applications to human gene therapy and neuronal physiology. Proc. Nat. Acad. Sci. USA. 87:8950-8954.

14. Lu, B., and H.J. Federoff. 1995. Herpes simplex virus type 1 amplicon vectors with glucocorticoid-inducible gene expression. Hum. Gene Ther. 6:419428.

15. Mesri, E.A., H.J. Federoff, and M. Brownlee. 1995. Expression of vascular endothelial growth factor from a defective herpes simplex virus type 1 amplicon vector induces angiogenesis in mice. Circ. Res. 76:161-167.

16. Black, P.L., H. Phillips, H.R. Tribble, R. Pennington, M. Schneider, and J.E. Talmadge. 1993. Antitumor response to recombinant murine interferon gamma correlates with enhanced immune function of organ-associated, but not recirculating cytolytic T lymphocytes and macrophages. Cancer Immunol. Immunother. 37:299-306.

17. Kawada, N., Y. Mizoguchi, K. Kobayashi, S. Morisawa, T. Monna, and S. Yamamoto. 1991. Interferon gamma modulates production of Interleukin 1 and tumor necrosis factor by murine Kupffer cells. Liver. 11:42-47.

18. Kutteh, W.H., W.E. Rainey, and B.R. Carr. 1991. Regulation of Interleukin-6 production in human fetal Kupffer cells. Scand. J. Immunol. 33:607613.

19. West, M.A., G.A. Keller, F.B. Xerra, and R.L. Simmons. 1985. Killed Escherichia coli stimulates macrophage mediated alterations in hepatocellular function during in vitro coculture: a mechanism of altered liver function in sepsis. Infect. Immun. 49:563-569.

20. Johnson, P., A. Miyanohara, F. Levine, T. Cahill, and T. Friedmann. 1992. Cytotoxicity of a replication-defective mutant of herpes simplex virus type I. J. Virol. 66:2952-2965.

21. Patterson, T., and R. Everett. 1990. A prominent serine-rich region in Vmw175, the major transcription regulator protein of herpes simplex virus type 1 , is not essential for virus growth in tissue culture. J. Gen. Virol. 71:1775-1783.

22. Geschwind, M., B. Lu, and H. Federoff. 1994. Expression of neu- 
rotrophic genes from herpes simplex virus type I vectors modifying neuronal phenotype. In Providing Pharmacological Access to the Brain: Alternative Approaches. T.R. Flanagan, D.F. Emerich, and S.R. Winn, editors. Academic Press, New York. 462-482.

23. Picardo, A., Y. Fong, H.M. Karpoff, S. Yeh, L.H. Blumgart, and M.F. Brennan. 1996. Factors influencing hepatocyte trafficking during allogenic hepatocyte transplantation: improved liver sequestration with isolated perfusion. J. Surg. Res. 63:452-459.

24. Balemans, L.T.M., V. Mattijssen, P.A. Sterenbertg, B.E.M. Van Driel, P.H.M. De Mulder, and W.D. Otter. 1993. Locoregional therapy with polyethylene-glycol-modified interleukin-2 of an intradermally growing hepatocellular carcinoma in the guinea pig induces T-cell-mediated antitumor activity. Cancer Immunol. Immunother. 37:7-14.

25. Ley, V., P. Langlade-Demoyen, P. Kourilsky, and E. Larrson-Sciard. 1991. Interleukin 2-dependent activation of tumor-specific cytotoxic T lymphocytes in vivo. Eur. J. Immunol. 21:851-854.

26. Schuurman, B., G. Heuff, R.H. Beelan, and S. Meyer. 1994. Enhanced killing capacity of human Kupffer cells after activation with human granulocyte/macrophage-colony stimulating factor and interferon gamma. Cancer Immunol. Immunother. 39:179-184.

27. Miyanohara, A., P.A. Johnson, R.L. Elam, Y. Dai, J.L. Witztum, I.M. Verma, and T. Friedman. 1992. Direct gene transfer to the liver with Herpes Simplex Virus Type 1 vectors: Transient production of physiologically relevant levels of circulating factor IX. New Biol. 4:238-246.

28. Yamashita, R., T. Hiraoka, I. Kamimoto, and Y. Miyauchi. 1986. Pre- vention of growth of metastases in rat liver by perioperative immunoactivation. Cancer Res. 46:3138-3141.

29. Pearson, H.J., J. Anderson, J. Chamberlain, and P.R.F. Bell. 1986. The effect of Kupffer cell stimulation or depression on the development of liver metastases in the rat. Cancer Immunol. Immunother. 23:214-216.

30. Xhang, F., A. zur Hausen, M. Grewe, and K. Decker. 1994. Rat liver macrophages express the $55 \mathrm{kd}$ tumor necrosis factor receptor, modulation by interferon-gamma, lipopolysaccharide and tumor necrosis factor-alpha. Biol. Chem. Hoppe-Seylar. 375:248-254.

31. Margolin, K.A., J.H. Doroshow, L.A. Leong, R.J. Morgan, J. Rashko, G. Somlo, B. Mills, D. Goldberg, and I. Sniecinski. 1992. Phase I trial of interleukin-2 plus gamma-interferon. J. Immunol. 11:50-55.

32. Iwanuma, Y., K. Kato, H. Yagita, and K. Okumura. 1995. Induction of tumor-specific cytotoxic T lymphocytes and natural killer cells by tumor cells transfected with the interleukin-2 gene. Cancer Immunol. Immunother. 40:1723.

33. Raper, S.E., M. Grossman, D.J. Rader, J.G. Theone, B.J. Clark, III, D.M. Kolansky, D.W.M. Muller, and J.M. Wilson. 1996. Safety and feasibility of liver directed ex vivo gene therapy for homozygous familial hypercholesterolemia. Ann. Surg. 223:116-126.

34. Tung, C., H.J. Federoff, M. Brownlee, H. Karpoff, T. Weigel, M.F. Brennan, and Y. Fong. 1996. Rapid production of IL-2 secreting tumor cells by HSV-mediated gene transfer: Implications for autologous vaccine production. Hum. Gene Ther. 7:2217-2221. 